\title{
PREMATURE EPIPHYSIAL FUSION AFTER INJURY OF THE CAPITULUM
}

\author{
ThOMAS G. WADSWORTH, LiVERPOOL, ENGLAND
}

It is well known that injury of the capitulum is both common and important in childhood. Although much has been written on the subject, the frequency and importance of premature fusion of the epiphysis has not been fully appreciated.

Clinical material-Twenty-eight children suffering from injury to the capitular epiphysis were reviewed. The age at the time of injury varied from three to twelve years and the follow-up period was from one to seventeen years.

In eight patients there was a fracture through the lower humeral metaphysis without displacement of the capitular epiphysis (Fig. 1), and in one of these a further injury resulted in a flake fracture of the infero-lateral margin of the capitulum.

In twenty patients the capitulum was displaced and rotated and in all of these there was the typical metaphysial fracture (Fig. 2). In two of these patients there was a vertical fracture through the inner part of the capitular ossification centre (Fig. 3).

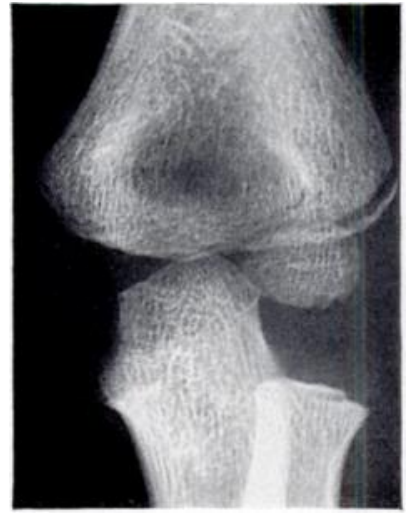

FiG. 1

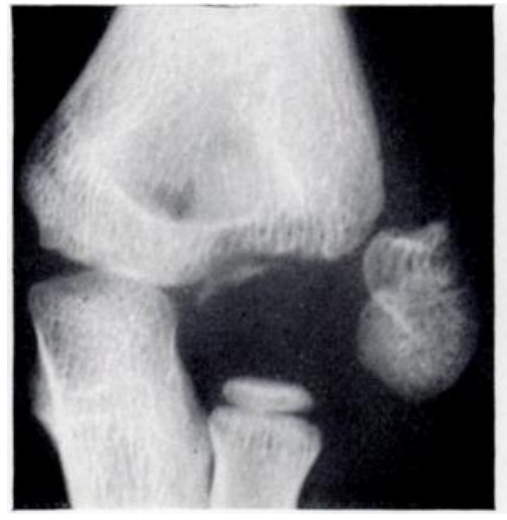

Fig. 2

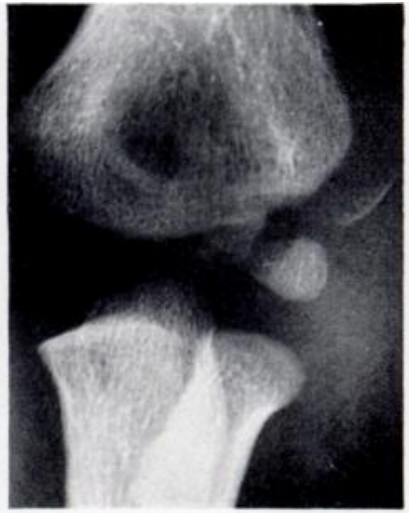

FIG. 3

Figure 1-Fracture through the lower humeral metaphysis without displacement of the capitular epiphysis. Figure 2-Displaced and rotated capitulum with the typical metaphysial fracture. Figure 3-Displaced and rotated capitulum with a metaphysial fracture and a vertical fracture through the inner part of the capitular ossification centre.

Treatment-The eight patients in the first group, that is those without displacement, were treated by immobilisation in a collar and cuff sling.

Of the twenty patients in the second group, with displaced fractures, four were treated by closed reduction and immobilisation in a collar and cuff sling. In the remainder, treatment was by operative reduction and fixation of the lateral condylar fragment to the lower humeral metaphysis by chromic catgut sutures; these sutures were passed through the antero-lateral and lateral aspects of the metaphysis and the soft tissues attached to the lateral condyle. Closed reduction had failed in five of these sixteen cases.

Premature epiphysial fusion-Premature epiphysial fusion was noted, when compared with radiographs of the opposite elbow, in six patients and these will be described. The valgus angle is expressed as " injured side/normal side." Some difficulty was experienced in measuring this angle when extension of the elbow was restricted (Cases 2, 4 and 5).

\section{CASE RFPORTS}

Case 1-A boy aged eight years fell from a wall directly on to the left elbow. There was a metaphysial fracture without displacement of the capitulum. The elbow was immobilised in a collar and cuff sling for three weeks. The patient was reviewed five years after the injury at the age of thirteen years. 
Elbow movements were full. There was a valgus deformity of 20/10 degrees. Radiographs showed premature fusion of the capitular and trochlear epiphyses, both of which had fused to the lower humeral metaphysis (Figs. 4 and 5).

Case 2-A boy aged four years sustained a metaphysial fracture of the left humerus with slight displacement of the capitulum. The elbow was immobilised by means of a plaster-of-Paris slab for two weeks. A further injury occurred at the age of twelve years, resulting in a flake fracture of the infero-lateral margin of the capitulum. The patient was reviewed ten years after the first injury at the age of fourteen years. Elbow movements were restricted: extension lacked 40 degrees but flexion was full. There was no valgus deformity. Radiographs showed premature fusion of the capitular and trochlear epiphyses to the lower humeral metaphysis (this was present eight years after the first injury).

Case 3-A boy aged six years fell directly on to the left elbow, causing severe displacement and rotation of the capitulum. Open reduction was carried out and when the patient was reviewed four years later there was no loss of movement or valgus deformity. Radiographs showed premature fusion of the antero-lateral part of the capitulum to the lower humeral metaphysis.

Case 4-A boy aged seven years fell on to the left elbow causing severe displacement and rotation of the capitulum. Closed reduction was unsuccessful and open reduction was carried out. The patient was reviewed six years later when flexion of the elbow was full and extension lacked 30 degrees. There was a valgus deformity of $20 / 10$ degrees. Radiographs showed premature fusion of the capitulum to the lower humeral metaphysis and a "fishtail deformity" (Figs. 6 and 7).

Case 5-A boy aged six years sustained a severely displaced and rotated left capitulum which was treated by open reduction. The patient was reviewed three years later when flexion of the elbow was full and extension lacked 10 degrees. There was a valgus deformity of 20/10 degrees and radiographs showed premature fusion of the capitulum to the lower humeral metaphysis and a " fishtail deformity " (Figs. 8 and 9).

Case 6-A boy aged five years sustained a slightly displaced and rotated left capitulum which was treated by open reduction. In addition to the metaphysial fracture there was a fracture through the inner part of the capitular ossification centre. The patient was reviewed four years later when there was no loss of movement or valgus deformity. Radiographs showed premature fusion of the capitulum to the lower humeral metaphysis and a "fishtail deformity"; the capitular fracture was ununited at the articular surface.

\section{DISCUSSION}

Sherren (1908) observed the development of premature synostosis after injury to the capitulum in childhood and this complication was observed after deliberately delayed open reduction by Speed and Macey (1933) and mentioned as a possibility by McDonnell and Wilson (1948). It has otherwise apparently escaped observation.

In this series it was noted in just over a fifth of the patients. The fusion of both capitular and trochlear epiphyses to the metaphysis in Case 1 followed a seemingly trivial injury as there was only a fine fracture line in the metaphysis; the injury occurred at the age of eight years and premature fusion was noted five years later. The associated valgus deformity was presumably due to accelerated fusion of the capitular epiphysis compared with the trochlear epiphysis. Exactly the same type of premature fusion in Case 2 followed an injury at the age of four years, but there was no valgus deformity.

Premature fusion of the capitular epiphysis to the metaphysis was seen in four patients after open reduction. The age at the time of injury was between five and seven years and premature fusion was noted from three to six years later. There was lack of growth in the outer part of the trochlea in three of these patients, resulting in a "fishtail deformity," and there was a valgus deformity in two of them.

Narrowing of the lower humeral epiphysial plate was observed in eleven of the other patients reviewed.

A study of twenty-eight cases of injury to the capitular epiphysis in childhood shows that premature fusion may be of two types. In the first type the capitular epiphysis fuses to the metaphysis and, as this epiphysis accounts for ossification of the outer part of the trochlea, leads to disturbance of growth, commonly referred to as a " fishtail deformity." In the second

VOL. 46 B, NO. 1, FEBRUARY 1964 


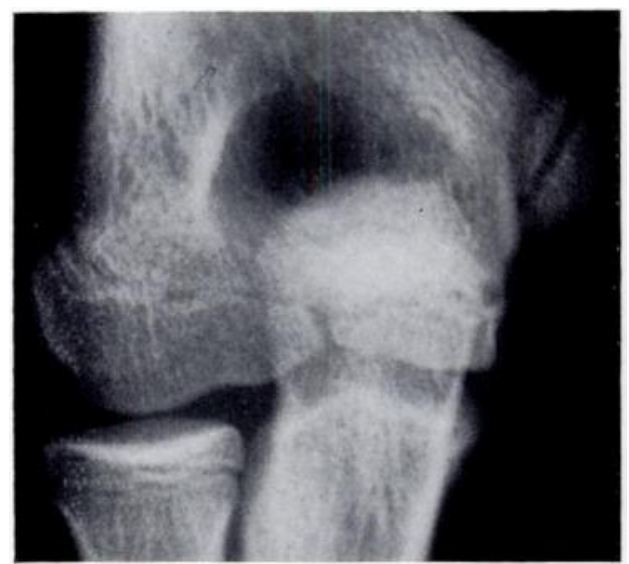

Fig. 4

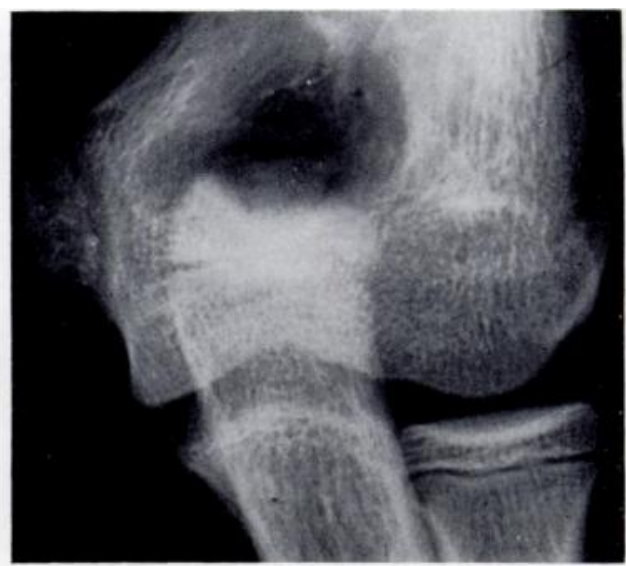

Fig. 5

Case 1. Figure 4-The normal elbow. Figure 5-Premature fusion between the capitular and trochlear epiphyses which are fused to the lower humeral metaphysis.

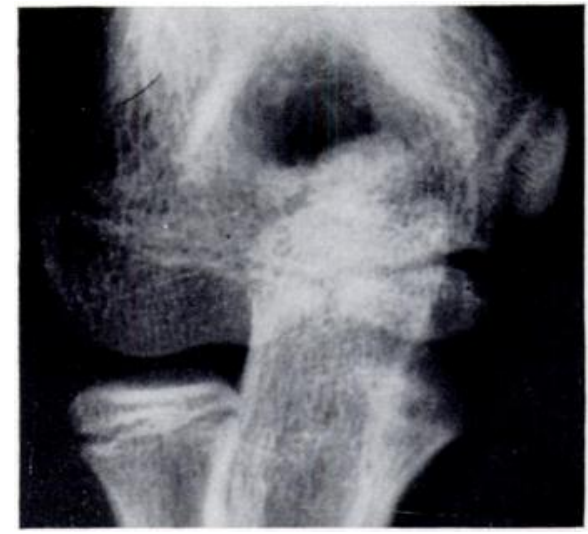

Fig. 6

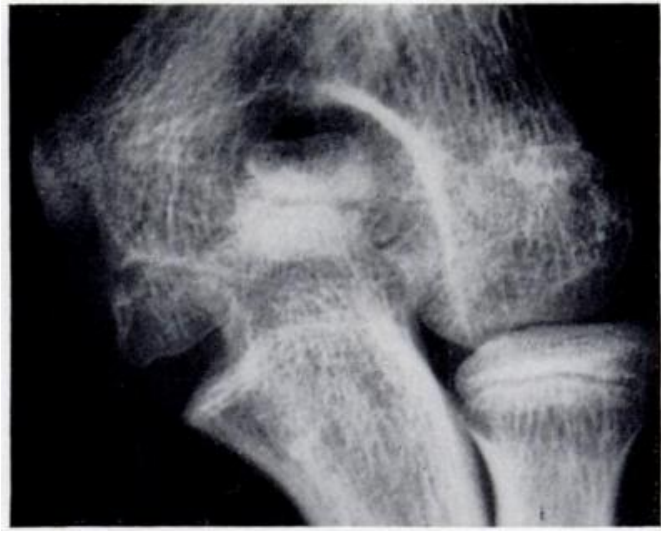

FIG. 7

Case 4. Figure 6-The normal elbow. Figure 7-Premature fusion of the capitulum to the lower humeral metaphysis and a "fishtail deformity."

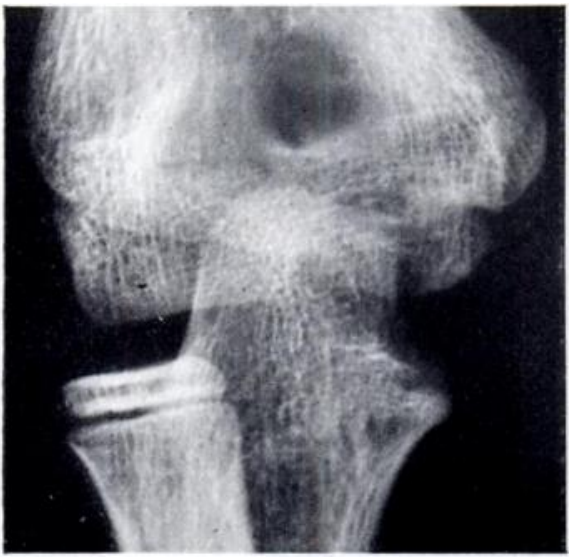

FIG. 8

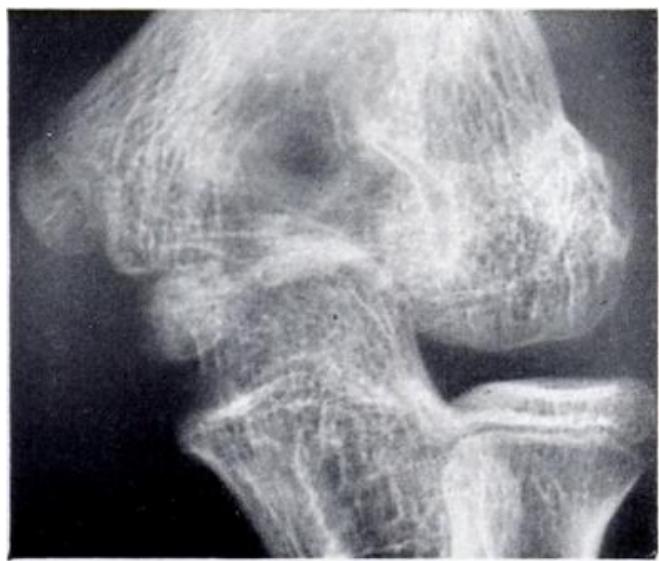

FIG. 9

Case 5. Figure 8-The normal elbow. Figure 9-Premature fusion of the capitulum to the lower humeral metaphysis and a "fishtail deformity." 
type the capitular and trochlear epiphyses fuse together and to the metaphysis and sometimes the capitular epiphysis fuses with the lower humeral metaphysis before the trochlear epiphysis. Radial shift of the ulna can follow premature fusion of either type and can result in cubitus valgus. Valgus deformity at the elbow, resulting from this injury, is rarely severe enough to cause unsightly deformity. However, McLearie and Merson (1954) pointed out that poor articulation of the ulna with the trochlea can cause impaired movement.

The most important complication of injuries to the capitular epiphysis in childhood is ulnar neuritis, commonly associated with cubitus valgus. This may be due to a simple compression by the band bridging the two heads of the flexor carpi ulnaris when the capacity of the "cubital tunnel" is less than normal, as described by Osborne (1957) and by Feindel and Stratford (1958). It is possible that the cause of the nerve lesion after this injury can be explained by the radial shift of the ulna due to lack of ossification in the outer part of the trochlea. Additional factors can be premature fusion, malunion, non-union and avascular necrosis of the capitulum.

Premature fusion in this series has been compared with radiographs of the opposite elbow. It is well known that there is considerable variation in the appearance and normal fusion of the lower humeral epiphyses and it must be remembered that skeletal development can vary between the right and left sides of the body. Dreizen, Snodgrasse, Webb-Peploe, Parker and Spies (1957) studied skeletal development in the hands of 450 children. They noted the right side to be in advance of the left in 52 per cent of cases, equal in 26 per cent and the left in advance of the right in the remaining 22 per cent of cases. They found that differences in skeletal age in the hands exceeded three months in 13 per cent of cases, but exceeded six months in only 1.5 per cent of the cases reviewed. Caffey (1961) stated that, as a rule, the secondary epiphysial centres of the tubular bones exhibit a more uniform development than the primary centres of the carpal bones. There does not seem to be any doubt, in the present series, that the premature epiphysial fusion was pathological.

\section{SUMMARY}

Premature epiphysial fusion is a common complication of injury of the capitulum in childhood and sometimes results in valgus deformity. Premature fusion can either follow the normal pattern of fusion, perhaps being accelerated on the capitular side, or it can be confined to the capitulum and metaphysis. An optimistic prognosis with regard to valgus deformity and the possible onset of ulnar neuritis cannot be made in view of this complication, even in the undisplaced or perfectly reduced and immobilised cases.

I would like to express my thanks for permission to review these cases to Mr A. G. O’Malley, Mr E. W. Knowles and the late Professor Bryan McFarland. I would especially like to thank Mr Goronwy Thomas for his kind help and advice during the preparation of this paper.

\section{REFERENCES}

Dreizen, S., Snodgrasse, R. M., Webb-Peploe, H., Parker, G. S., and Spies, T. D. (1957): Bilateral Symmetry of Skeletal Maturation in the Human Hand and Wrist. American Journal of Diseases of Children, 93, 122.

Caffey, J. (1961): Pediatric X-ray Diagnosis. Fourth edition. Chicago: Year Book Medical Publishers Inc.

Feindel, W., and Stratford, J. (1958): Cubital Tunnel Compression in Tardy Ulnar Palsy. Canadian Medical Association Journal, 78, 351.

MCDonnell, D. P., and Wilson, J. C. (1948): Fractures of the Lower End of the Humerus in Child ren. Journal of Bone and Joint Surgery, 30-A, 347.

McLearie, M., and Merson, R. D. (1954): Injuries to the Lateral Condyle Epiphysis of the Humerus in Children. Journal of Bone and Joint Surgery, 36-B, 84.

OsBorne, G. V. (1957): The Surgical Treatment of Tardy Ulnar Neuritis. Journal of Bone and Joint Surgery, 39-B, 782.

Sherren, J. (1908): Remarks on Chronic Neuritis of the Ulnar Nerve, due to Deformity in the Region of the Elbow-joint. Edinburgh Medical Journal, N.S. 23, 500.

SPEED, J. S., and MACEY, H. B. (1933): Fractures of the Humeral Condyles in Children. Journal of Bone and Joint Surgery, 15, 903.

VOL. $46 \mathrm{~B}$, NO. 1, FEBRUARY 1964 